\title{
Mitral Valve Atresia
}

National Cancer Institute

\section{Source}

National Cancer Institute. Mitral Valve Atresia. NCI Thesaurus. Code C98992.

A congenital heart defect characterized by the complete atresia of the mitral valve. 